\title{
HERPES ZOSTER OPHTHALMICUS AND POST-HERPETIC NEURALGIA
}

\author{
BY \\ W. F. T. TATLOW \\ From the Maida Vale Hospital for Nervous Diseases, London
}

Jonathan Hutchinson (1865-6) was the first person to distinguish herpes zoster ophthalmicus from erysipelas, and he described 18 cases, one of which developed a third nerve palsy. Hutchinson stated that zoster never affected the cheek at all, but a few years later Head and Campbell (1900) described a case with affection of the mandibular branch; Paton (1926) reported a case with involvement of both cheek and forehead; and O'Neill (1945) described what he considered to be the first case with involvement of the first, second, and third divisions of the trigeminal nerve, but in his case there was also involvement of the seventh and eighth cranial nerves.

Various palsies of the extraocular nerves may occur, and the incidence according to WorsterDrought (1923) is $7 \%$ of cases with ophthalmic herpes zoster. The commonest nerve to be paralysed according to Moore (1932) is the third, and forms $74 \%$ of the extraocular nerve pareses; Edgerton (1942) states that the third nerve was the commonest extraocular nerve to be paralysed and occurred 96 times in the literature. Edgerton (1942), in his review of the literature, stated that paralysis was found usually after, sometimes with, and occasionally before, the skin eruption; he goes on to comment that paralysis of the extraocular nerves is due to " encroachment of the inflammation in the region of the cavernous sinus": this is probably incorrect as the lesion has been shown to be in the anterior horn cells when muscular paralysis occurs elsewhere, so there is no reason to postulate a different pathology so far as the eye palsies are concerned. Other cases of herpes zoster ophthalmicus with intraocular or extraocular muscular palsies have been described by ParkesWeber (1916), Hall (1903), and Mules (1903). Mules also suggested that ocular palsies could occur without an eruption of zoster, i.e. formes frustes.

Batignani (1934) reported a case of moderate exophthalmos with total ophthalmoplegia ; Car- mody (1937) described severe exophthalmos in the course of herpes zoster ophthalmicus and more recently Donahue (1946) described a case of ophthalmic herpes zoster with the development of complete external ophthalmoplegia occurring during the eighth week of the disease.

Achard and Castaigne (1897) described a permanent paralysis with dilation of the left pupil after an attack of ophthalmic zoster, and ParkesWeber (1916) suggested, as had Mules, that unexplained mydriasis and attacks of paresis in isolated muscles or muscle groups, with or without sensory loss, might be " herpes zoster sine herpete".

The age of onset of ophthalmic herpes zoster in 2,250 cases reviewed by Edgerton (1942) was 44, with a sex incidence of $54 \%$ males: the same author also recorded a low incidence of herpes zoster ophthalmicus, there being five cases out of 30,000 patients at an eye hospital during one year.

\section{Pathology}

Von Barensprung (1863) was the first to perform a post-mortem examination on a case of zoster and found a lesion in the posterior root ganglion. Sattler (1875) reported a case of herpes zoster ophthalmicus where a necropsy was performed 14 days after the onset; the Gasserian ganglion was found to be infiltrated with small, round cells and there was destruction of the ganglion cells. Head and Campbell (1900) investigated very fully the pathological changes at the posterior root ganglia, and Denny-Brown, Adams, and Fitzgerald (1944), summarizing the pathology, state: "The present concept of herpes zoster is an acute inflammatory reaction in isolated spinal or cranial sensory ganglia, posterior grey matter of cord or adjacent leptomeninges ". The lesion in their cases resembled an infarct necrosis with ganglionitis marked by necrosis of all or part of the ganglion with or without haemorrhage; in addition there was poliomyelitis with a mild leptomeningitis localized to affected 
segments, and lastly a true peripheral mononeuritis.

Brown and Dujardin (1919) investigated the cerebrospinal fluid in herpes zoster; they found that there was a variable lymphocytic response, but that it bore no relation to the intensity of eruption, to age, or to the stage of disease, and varied from normal to $\mathbf{4 7 0}$ lymphocytes per c.mm.

\section{Vascular Supply of the Gasserian Ganglion}

Bergmann (1942) quotes Meckel (1748) as making the first observation on the arterial supply of the trigeminal ganglion. Bergmann found that there was most constantly an arch on the medial side of the ganglion around the emerging primary divisions : the convexity of this arch is forwards from a small branch off the internal carotid artery, the lower part from the middle mengingeal or small meningeal arteries, and also from a branch of the internal maxillary artery through the foramen rotundum and occasionally through the foramen lacerum.

Truex (1940) investigated changes which occurred with age in the Gasserian ganglion. He examined ganglia from necropsies with age variations from 28 months to 66 years, and he found that fatty degeneration of sensory ganglion cells appeared to be the cause of loss of many neurons after middle age. He suggested that it might cause decreased sensitivity after the third decade. He also concluded that elastic intimal thickening in axial arteries suggested that vascular disturbances might be a factor in these degenerative processes. These factors may explain the greater incidence of postherpetic pain in older people.

\section{Present Investigation}

Fifty-eight unselected patients who had had herpes zoster ophthalmicus and had attended Moorfields Eye Hospital, London, from 1941 to 1948 were investigated with special reference to the incidence of post-herpetic pain.

The average age of onset was 53.7 years in 57 of the 58 patients, (the age of one patient, who was later untraced was not recorded), and the ages varied from 19 to 85 . There was no significant difference in the sex incidence : 27 females and 31 males.

Of the 58 patients, no case showed any affection other than on the first division alone, and, although the series is a small one, this collaborates the rarity of affection of the other divisions as reported by other authors. The right side was affected in 33 cases and the left in 24 cases, the side in an untraced case being unrecorded.

The 58 patients were sent a postal questionnaire asking about the presence of pain on the area involved with the shingles and also the presence of any " numbness". Forty-seven patients answered, the remaining 11 being untraced. Only one patient had had such severe pain as to necessitate any radical treatment, an alcoholic injection in the Gasserian ganglion; unfortunately this patient could not be examined as he had died : no other patient had had deep $x$-ray treatment, leucotomy, or prolonged medical treatment. Three other patients had also died before follow-up, but, according to relatives, had had no persistent pain after the herpes. Forty-three patients who were living answered the questionnaire; 14 of these were not examined, and their history should, therefore, not be accepted in great detail, but two patients with " numbness" reported that they had " pain when tired", one patient had numbness but no pain, and the rest had neither numbness nor pain.

Twenty-nine patients were examined; all the patients had had pain in the face and in the eye during the period of vesicle formation and for some weeks before the lesions healed, but 13 patients (aged 51, 34, 71, 51, 60, 36, 19, 61, 51, 33, 66, 41, and 54 at the onset of the herpes) had had no pain or irritation whatsoever afterwards and, excluding corneal scarring and optic pallor, had no pupillary changes or any sensory loss at all except where skin scarring was severe. Eight patients, with no abnormal painful sensations whatsoever, had varying pupillary and sensory abnormalities which are discussed later. As regards the incidence of pain, $2 \mathbb{O}$ one patient with no sensory loss or pupillary abnormality had a "dull aching sort of pain in the forehead since", which was worse with worry orô․ fatigue. Seven other patients had painful sen-? sations varying in degree from a " pricking irritation" to "sharp, stabbing, neuralgic pains". In all these patients there was some form of sensory loss corresponding to the anatomical distribution of the first division of the fifth nerve.

\section{Case Reports}

Case 1.-A woman, aged 49, had herpes zoster affecting the left ophthalmic division in 1948. She was still having occasional "pin pricks" and frequent "itching" in the forehead. She was found to have blunting of wool, pain, and temperature sensation in the distribution of the first division of the fifth nerve. She described herself as a nervous, worrying person, but had never had any nervous breakdowns.

Case 2.-A man, aged 39, had herpes zoster affecting the right ophthalmic division in 1948. He was still having occasional " pricking " sensations in the forehead. He was found to have blunting of all sensory modalities in the distribution of the first division of the fifth nerve. He described himself as a nervous, worrying type, and had been discharged from the R.A.F. on account of neurosis. 
DETAILS OF CASES IN PRESENT SERIES

\begin{tabular}{|c|c|c|c|c|c|c|c|c|c|c|c|}
\hline & & \multirow{2}{*}{ Total } & \multicolumn{8}{|c|}{ Ages (in years) } & \multirow[b]{2}{*}{ Unrecorded } \\
\hline & & & $<20$ & $<30$ & $<40$ & $<50$ & $<60$ & $<70$ & $<80$ & $<90$ & \\
\hline Total & $\cdots$ & 58 & 1 & 1 & 7 & 14 & 15 & 16 & 2 & 1 & 1 \\
\hline \multicolumn{2}{|c|}{ Total traced (including those dead) } & 47 & 1 & 1 & 6 & 11 & 12 & 13 & 2 & - & 1 \\
\hline Total examined & . & 29 & 1 & - & 5 & 9 & 8 & 5 & 1 & - & - \\
\hline Sensory loss . . & . $\quad \cdots$ & $12(2)$ & - & - & 2 & $6(1)$ & 3 & $1(1)$ & - & - & - \\
\hline \multicolumn{2}{|c|}{ Sensory loss with painful sensations } & $7(2)$ & - & - & 2 & $3(1)$ & 1 & $1(1)$ & - & - & - \\
\hline \multicolumn{2}{|c|}{ Pain without sensory loss .. } & $1 *$ & - & - & - & - & 1 & 一 & - & - & - \\
\hline \multicolumn{2}{|c|}{$\begin{array}{c}\text { Percentage of painful sensations in } \\
\text { patients examined }\end{array}$} & - & - & - & $40 \%$ & $33 \%$ & $12 \cdot 5^{\circ}$, & $20 \%$ & - & - & - \\
\hline \multicolumn{2}{|c|}{ No. with pupillary abnormalities.. } & 6 & - & - & 1 & - & 3 & 2 & - & - & - \\
\hline
\end{tabular}

Figures in parentheses indicate patients not examined.

*Denotes pain described as "dull aching".

Case 3.-A woman, aged 50, had herpes zoster affecting the right ophthalmic division in 1946. She still had quite severe post-herpetic pain, which she described as a "severe toothache like a nerve exposed", in the forehead. She was found to have considerable blunting of pain and touch sensation; temperature sense was abnormal, heat producing a prickling sensation and cold a hyperpathia in the distribution of the first division of the fifth nerve. She described herself as a normal person, and not subject to any nervous disability: she had been separated from her husband for some years and had been at work for 24 years.

Case 4.-A woman, aged 41, had herpes zoster affecting the right ophthalmic division in 1944. She still had an occasional "pricking sensation", but it was only felt in the scarred area of the skin. She was found to have very severe skin scarring, and the only sensory loss (which was to all modalities) was in this area. She described herself as a nervous person and had had a " nervous breakdown" in the blitz.

Case 5.-A man, aged 34, had herpes zoster affecting the left ophthalmic division in 1942. He was still having an occasional "burning irritation" in the forehead, but only when he was worried or anxious. He was found to have abnormal skin sensation : testing with pain produced a burning sensation, and there was also a hyperpathic response to touch and temperature of the first division of the fifth nerve.

Case 6.-A woman, aged 46, had herpes zoster affecting the right ophthalmic division in 1948. She was still having occasional smarting, burning, " neuralgic" pains in the forehead. She was found to have diminution of touch and pain sensibility over the distribution of the first division of the fifth nerve. She described herself as a very nervous person, and had had a nervous breakdown in the past.

Case 7.-A woman, aged 61, had herpes zoster affecting the left ophthalmic division in 1941. She was still having occasional itching and tingling in the forehead. She was found to have reduction of pain, temperature, and touch sensation over the first division of the fifth nerve. She described herself as a normal person and was not a worrying, anxious type.

From the histories of these patients there appears to be a distinct correlation between sensory loss and abnormal sensation. One patient, previously described, had what she called an " ache" in the forehead, but no sensory loss at all : all the other seven patients with pain or abnormal sensation had definite sensory loss or hyperpathia. In addition, five other patients had sensory loss over the first division of the fifth nerve which had been affected by herpes. These five patients described themselves as normal persons who were not worriers and had never had any nervous breakdowns. Although the number of patients in this series is small the impression left is that it is the worrying, anxious type with sensory loss who may develop abnormal pain sensations.

Six of the 29 patients examined had abnormal pupillary responses which could not be accounted for by corneal scarring or blindness. The abnormal pupils, occurring on the same side as the herpes zoster, showed no reaction to direct or consensual light at all, but responded well on accommodation. They could not be regarded as true Argyll Robertson pupils, as they were not always small, were not irregular, and showed no changes in pigmentation of the iris, but the high percentage of patients showing such an abnormality was surprising.

\section{Discussion}

The aetiology of post-herpetic neuralgia is unknown, but it has been suggested that it may be assc- 
ciated with vascular changes due to arteriosclerosis, as it is more frequent in elderly people. In this small series there was no apparent correlation with age at all, and this suggests that vascular changes are not a definite factor. The incidence of postherpetic neuralgia appears small ; only one patient had had severe neuralgia requiring injection (although most authorities agree that this has no therapeutic effect anyway), and seven others had uncomfortable paraesthesiae. All the patients who were examined and had these paraesthesiae had a marked sensory loss corresponding to the distribution of the sensory symptoms, but there must be some other aetiological factors involved as five other patients had sensory loss, but no paraesthesiae. Psychogenic factors have an important bearing on the subject of the pain, and this has been corroborated by the results of frontal leucotomy. In this investigation there was an impression that the patient who continued to have pain after herpes zoster was of the introspective, worrying type, but always in association with sensory loss : the pain was, in fact, always made worse by worry and tiredness. The pain appears gradually to improve as time passes, but can continue for a number of years : it is never delayed in onset, always being present from the start of the vesicle formation.

The pupillary abnormalities in these cases did not appear to be associated necessarily with either pain or sensory loss, three of the patients having no sensory abnormalities at all, nor could these abnormalities be correlated in any way with the severity of the attack of herpes. Pseudo Argyll-Robertson pupils have been reported in herpes zoster ophthalmicus by Guillain, Lagrange, and Perisson (1926) and Valière-Valeix (1931). Nathan and Aldren Turner (1941) described pseudo Argyll-Robertson pupils in cases of traumatic lesions to the peripheral efferent pathway. They suggested that accommodation-convergence fibres might by-pass the ciliary ganglion and go direct to the episcleral ganglia described by Axenfeld (1907) and Givner (1939), and that this might explain the presence of accommodation-convergence responses and the absence of light reflexes in such traumatic lesions. Their arguments are not necessarily valid because their cases had had third nerve palsies, and such pseudo ArgyllRobertson pupils may be due to abnormal regeneration of the oculo-motor nerve, as has been reported by Ford, Walsh, and King (1941), by Bender (1945), and by Ritchie Russell and Wright (1948). In the cases reported in this series no third nerve palsy had been observed previously, and therefore synkinetic pupillary phenomena due to a recurring third nerve palsy could be excluded. The exact anatomical site of the lesion is doubtful in the absence of post- mortem material, but in the absence of gross change in visual acuity and of a consensual light response, the site of the lesion to account for these pseudo Argyll-Robertson pupils could be in the ciliary ganglion.

\section{Summary}

Fifty-eight patients who had had herpes zoster ophthalmicus were investigated : 47 were traced, and in only one patient had alcoholic injection been given for severe pain.

Twenty-nine patients were examined, and of these seven had persistent pain or abnormal sensations.

The seven patients with pain or abnormal sensations were all found to have diminution of some sensory modalities.

Five other patients examined also had sensory diminution, but did not have any pain or other abnormal sensation.

Six out of the 29 patients examined had pupils which did not react at all to direct or consensual light, but reacted well to accommodation.

I am grateful to the consultant surgeons of Moorfields Eye Hospital for permission to follow-up and examine their cases, and especially to Mr. Robert Davenport, Senior Surgeon, for arranging for me to do so.

\section{REFERENCES}

Achard, C., and Castaigne, J. (1897). Gaz. hebd. Méd. n.s. Paris, 2, 1177.

Axenfeld, T. (1907). Ber. ophthal. Ges. Heidelberg, 34, 300.

Barensprung, von (1863). Ann. Charité-Krankenhauses, $11,96$.

Batignani, A. (1934). Boll. Oculist., 13, 814.

Bender, M. B. (1945). Arch. Neurol. Psychiat., Chicago, $53,418$.

Bergmann, L. (1942). Anat. Rec., 82, 609.

Brown, W. H., and Dujardin, B. (1919). Brain, 42, 86.

Carmody, R. F. (1937). Arch. Ophthal., Chicago, 18, 707.

Denny-Brown, D., Adams, R. D., and Fitzgerald, P. J. (1944). Arch. Neurol. Psychiat., Chicago, 51, 216.

Donahue, H. C. (1946). Amer. J. Ophthal., 29, 582.

Edgerton, A. E. (1942). Trans. Amer. ophthal. Soc., 40, 390.

Ford, F. R., Walsh, F. B., and King, A. (1941). Bull. Johns Hopk. Hosp., 68, 309.

Givner, I. (1939). Arch. Ophthal., Chicago, 22, 82.

Guillain, G., Lagrange, H., and Perisson, J. (1926). Bull. Soc. Ophthal., Paris, p. 227.

Hall, A. (1903). Brit. J. Derm., 15, 311.

Head, H., and Campbell, A. W. (1900). Brain, 23, 353. Hutchinson, J. (1866). Roy. Lond. ophthal. Hosp.Rep., $5,191$.

Meckel, J. F. (1748). 'De Quinto pare nervorum cerebri'. Gottingen.

Moore, R. F. (1932). Brit. med. J., 2, 783.

Mules, P. H. (1903). Lancet, 1, 523. 
Nathan, P. W., and Aldren Turner, J. W. (1942). Brain, 65,343 .

O’Neill, H. (1945). Arch. Ophthal., Chicago, 33, 237.

Paton, L. (1926). Brit. J. Ophthal., 10, 305.

Russell, W. Ritchie, and Wright, M. H. (1948). Journal of Neurology, Neurosurgery and Psychiatry, 11, 288.
Sattler, H. (1875). Anz. Ges. Aerzte Wien, No. 3, p. 11. In Med. Jh., 1876.

Truex, R. C. (1940). Amer. J. Path., 16, 255.

Valière-Vialeix, V. (1931). Ann. Oculist., Paris, 168, 341.

Weber, F. Parkes (1916). Brit. J. Derm., 28, 13.

Worster-Drought, C. (1923). Brit. med. J., 1, 970.

\section{Third Symposium Neuroradiologicum}

The third Symposium Neuroradiologicum will be held in Stockholm on September 17-20, 1952. The president is Professor Erik Lindgren, Stockholm. All those wishing to attend should send in their names and addresses to the Secretary, Symposium Neuroradiologicum, Serafimerlasarettet, Stockholm, Sweden.

\section{International Meeting of Neuropathologists}

The first international meeting of neuropathologists will be held in Rome from Monday, September 8, to Saturday, September 13, 1952. The President is Dr. Mario Gozzano (Rome), and the Secretary General, Dr. Armando Ferraro (New York).

Final arrangements are now being made for the programme. It has been decided that the following subjects should be discussed, one day being devoted to each subject: (1) histopathology of the demyelinating diseases; (2) histopathology of vascular diseases ; (3) histopathology of schizophrenia ; (4) histopathology of mental deficiencies; and (5) histopathology of senility.

Also part of one or more days will be devoted to short papers of special interest not related to the above subjects and to cinematographic and microscopical demonstrations.

The British Committee will be glad to receive offers of short papers for this meeting, especially of papers related to the five main topics. Those who wish to read papers should communicate with Dr. J. G. Greenfield at the National Hospital, Queen Square, London, W.C.1, or with any member of the British Committee, giving the full title of the paper and a summary showing in what respects it covers new ground.

British Committee: Dr. J. G. Greenfield, Hon. President ; Prof. Dorothy S. Russell, Vice-President ; Prof. J. H. Biggart; Prof. A. Meyer; Dr. W. Blackwood; Dr. W. H. McMenemey ; Dr. R. M. Norman. 